\title{
Long-term overgrazing restricted the proliferation of shrubs in a desert steppe
}

\author{
Baolong Yan ${ }^{1}$, Shijie $\mathrm{Lv}^{1}$, Xiaohui Song ${ }^{1}$, Zhanwen Wang ${ }^{1}$, Zhongwu Wang ${ }^{1}$, and Guodong \\ $\operatorname{Han}^{1}$ \\ ${ }^{1}$ Inner Mongolia Agricultural University
}

March 31, 2021

\begin{abstract}
Maintenance of a desirable mixture of shrubs and grasses is a key issue in sustainable grazing management. The aim of this study was to explore the effect of long-term sheep grazing on desert steppe shrubs. Based on a long-term controlled sheep stocking rate experiment in a desert steppe of north China, combined with long-term random sampling monitoring of aboveground vegetation standing crop (14 years) and short-term systematic sampling monitoring of vegetation cover and individual characteristics of shrubs (3 years), we analyzed plant community changes, the current situation of shrubs and the response of individual shrub characteristics to stocking rate. We found that low stocking rates have increased the cumulative above-ground standing crop of shrubs and herbaceous plants, but the cumulative above-ground standing crop of shrubs under high grazing rates tends to be flat. The cover and height of four shrub species generally showed a decrease with increasing stocking rate, while the response of the four shrubs to the stocking rate gradient varied. Among four shrub species, Artemisia frigida was the most sensitive to stocking rate, followed by Ceratoides latens and Caragana microphylla, while Kochia prostrata was relatively insensitive to stocking rate. These results suggest that grassland managers can use an appropriate stocking rate to maintain desirable plant community composition and configuration in the temperate grassland.
\end{abstract}

Long-term overgrazing restricted the proliferation of shrubs in a desert steppe

Baolong Yan ${ }^{\mathrm{a}, \mathrm{b}}$ Shijie $\mathrm{Lv}^{\mathrm{a}}$ Xiaohui Song ${ }^{\mathrm{a}}$ Zhanwen Wanga Zhongwu Wang ${ }^{\mathrm{a}} 11^{*}$ Corresponding author: Zhongwu Wang (E-mail:zhongwuwang1979@163.com; Tel: 86-471-3985242) Guodong Han ${ }^{\mathrm{a}}$

${ }^{a}$ College of Grassland, Resources and Environment/Key Laboratory of Grassland Resources of the Ministry of Education/Inner Mongolia Key Laboratory of Grassland Management and Utilization/Key Laboratory of Forage Cultivation, Processing and High Efficient Utilization of the Ministry of Agriculture, Inner Mongolia Agricultural University, Hohhot 010011, China.

b Agricultural College, Inner Mongolia University for Nationalities, Tongliao, 028000, China.

\section{Abstract}

Maintenance of a desirable mixture of shrubs and grasses is a key issue in sustainable grazing management. The aim of this study was to explore the effect of long-term sheep grazing on desert steppe shrubs. Based on a long-term controlled sheep stocking rate experiment in a desert steppe of north China, combined with long-term random sampling monitoring of above-ground vegetation standing crop (14 years) and short-term systematic sampling monitoring of vegetation cover and individual characteristics of shrubs (3 years), we analyzed plant community changes, the current situation of shrubs and the response of individual shrub characteristics to stocking rate. We found that low stocking rates have increased the cumulative aboveground standing crop of shrubs and herbaceous plants, but the cumulative above-ground standing crop of shrubs under high grazing rates tends to be flat. The cover and height of four shrub species generally showed 
a decrease with increasing stocking rate, while the response of the four shrubs to the stocking rate gradient varied. Among four shrub species, Artemisia frigidawas the most sensitive to stocking rate, followed by Ceratoides latens and Caragana microphylla, while Kochia prostratawas relatively insensitive to stocking rate. These results suggest that grassland managers can use an appropriate stocking rate to maintain desirable plant community composition and configuration in the temperate grassland.

\section{KEYWORDS}

temperate grassland; stocking rate; standing crop; plant cover; qualitive characteristics

\section{Introduction}

Herbivore grazing is an ecological and economic use of grasslands worldwide and is a primary disturbance affecting the plant community (Asner et al., 2004). Although maintenance of a desirable mixture of shrubs and herbaceous plants is beneficial to the functions and services of the grassland ecosystem (Barbosa da Silva et al., 2016), grazing management can intentionally or unintentionally change the abundance and distribution of shrubs and herbaceous plants in the community (Madany et al., 1983; Brown et al., 1999). Many studies have found that long-term grazing can reduce grass cover, and aboveground and belowground biomass, which not only increases resource availability for the recruitment of shrubs and facilitates shrub regeneration, but also reduces surface combustibles, which may reduce fire frequency (Archer, 1994; Lin et al., 2010; Lohmann et al., 2014). These effects change grassland vegetation structure from herbaceousto shrub-dominated communities and can accelerate the process of shrub encroachment (Case and Staver, 2017; Devine et al., 2017). For example, studies in savanna grassland suggest that overgrazing reduces grass cover and shifts dominant herbaceous plants from perennial to annual species, which have been linked with reductions in competition between shrubs and grasses, ultimately facilitating shrub development (Goheen et al., 2004; Belsky and Blumenthal, 2010; Graz, 2010; February et al., 2013). Studies in the western United States have shown that increasing density of grassland shrubs is related to the introduction of cattle grazing, because livestock can be used as a carrier for shrub seed diffusion while feeding on grassland plants (Painter et al., 1993; Tews et al., 2004). In contrast, other findings in semiarid north Chinese steppes have shown that grazing is not a direct cause of encroachment (Zhang et al., 2014) and some studies have even shown that grazing delays or limits shrub encroachment in a subhumid south American grassland (Altesor et al., 2006). In the latter case, grazing by domestic animals kept the shrubs at a smaller size and a low or static density, while shrub size and density increased with removal of the grazers (Friedel, 1985; Van Auken, 2009). Similarly, grazing exclusion in the temperate steppe in northern China has led to Caragana micropylla invasion, because of preferential utilization of palatable shrubs by grazers, such that after grazing exclusion vegetation species composition shifts from more to less palatable species due to the release of herbivore feeding pressure on grasses (Zhang et al., 2014). It has also been suggested that livestock consumption of seedlings and young branches of shrubs delays shrub development, suppressing their ability to compete with the dominant herbaceous plants (de Dios et al., 2014), and even causing shrub frequency to decrease or disappear.

There are often different shrub species on the grassland that form the 'background plant' of the plant community, giving the vegetation structure a clear mosaic pattern (Wei et al., 2013). Although there are many shrub species in grasslands, only a few species have actually become aggressive encroachers in regional flora (Stockes et al., 2010; Eldridge et al., 2011). For example, in a Sonoran Desert grassland, the coverage of Prosopis velutina increased markedly from the 1950s to the 1990s, whereas other shrubs have maintained low coverage (Brikes, 2017). Therefore, shrub proliferation depends not only on external driving factors, but also on the characteristics of the shrub itself (Van Auken, 2009). From the perspective of community theory, population distribution and species richness are the result of a regional species pool passing through a series of abiotic environment and biotic community processes, such that species with unsuitable environmental traits are excluded from the community (Keddy, 1992). Invasive shrubs must have a strong response to at least one encroachment driver, but must also overcome all other environmental factors in order to survive. Non-invasive shrubs may not respond to this driving factor, or may be limited by other environmental factors. 
In summary, the direction of succession in grassland plant communities under grazing disturbance is the result of the interaction of grazing livestock and shrub characteristics. When shrubs are consumed selectively by grazing livestock, shrubs in the plant community will be at a disadvantage, and when grazing animals mainly feed on herbaceous plants, the herbaceous plants will be at a disadvantage (Van Auken and Smeins, 2008). Therefore, the succession of grassland vegetation should be comprehensively judged according to the regional climate, dominant plant species and grazing animals.

The Stipa breviflora desert steppe is located in the transition zone of the Eurasian steppe from the typical steppe zone to the desert zone. The vegetation in this transition zone is shaped by the influence of a harsh climatic environment and scarce soil resources, and the ecosystem is sensitive to interference. More than 10 years of monitoring has shown that there are more than 60 plant species in the community, including shrubs and semi-shrubs such as Artemisia frigida, Kochia prostrata, Caragana microphylla and Ceratoides latens . Long-term research was carried out in this region to answer the following three questions. First, does shrub encroachment in Stipa breviflora desert steppe increase with the introduction of sheep grazing? Second, how do shrub species respond to grazing under different stocking rates? And third, can biotic or abiotic factors predict the direction of succession in the desert steppe under different stocking rates? Elucidating these questions can not only deepen our understanding of shrub-herbaceous plant interactions and succession patterns in desert steppe vegetation, but also provide a theoretical basis and experimental evidence to guide grazing management in desert grasslands to improve the ecological environment.

\section{Materials and methods}

\subsection{Study site}

The study site was located in Siziwang Banner (41\%46'43.6” N, 111deg53'41.7" E, $1456 \mathrm{~m}$ a.s.l.) in Inner Mongolia, northern China. The region has a temperate continental arid and semi-arid climate, which is dry and windy in spring and hot in summer. Mean annual precipitation was $220.00 \mathrm{~mm}$ and mean annual temperature was $3.80 \mathrm{degC}$ (from 2004 to 2018). Minimum temperature was $-16.22 \mathrm{degC}$ in January and maximum temperature was $21.14 \mathrm{degC}$ in July (from 2004 to 2018). Rainfall is mainly concentrated in May to August, with a humidity of $15 \%$ to $30 \%$. The frost-free period is 175 days. The main soil type is calcic Kastanozem (FAO soil classification). Soil texture is sandy loam with $71.23+-3.98 \%$ sand, $15.97+-2.87 \%$ silt, and $12.81+-2.69 \%$ clay. The total carbon, total nitrogen, available nitrogen, available phosphorus, available potassium and $\mathrm{pH}$ were $13.56 \mathrm{~g}^{*} \mathrm{~kg}^{-1}, 1.41 \mathrm{~g}^{*} \mathrm{~kg}^{-1}, 8.08 \mathrm{~g}^{*} \mathrm{~kg}^{-1}, 8.30 \mathrm{mg} \mathrm{kg}^{-1}, 50.58 \mathrm{~g}^{*} \mathrm{~kg}^{-1}$ and 10.57, respectively. The vegetation in the desert steppe is dominated by Stipa breviflora, Artemisia frigida, and Cleistogenes songorica, with average vegetation height of $8 \mathrm{~cm}$ and a canopy cover ranging from $17 \%$ to $20 \%$.

\subsection{Experimental design}

Twelve adjacent plots (each ca. $4.40 \mathrm{hm}^{2}$ ) were established at a grazing experiment site in 2004. These plots were arranged in a randomized complete block design, which included four stocking rate treatments with three replicates of each treatment (Figure 1 ). The stocking rates applied in each treatment were 0 , $0.91,1.82,2.71$ sheep* $\mathrm{hm}^{-2} *$ half $\mathrm{yr}^{-1}$, representing no grazing (CK), light grazing (LG), moderate grazing (MG), and heavy grazing (HG), respectively, with 4 grazing sheep in the LG treatment, 8 sheep in MG and 12 sheep in HG. Seasonal grazing started on 1 June and ended on 31 November in each year since 2004. The initial sheep from the same cohort were 2-year old Mongolian wethers and individuals were replaced after 3 years. The daily grazing schedule was from 6:00 am to 6:00 pm. Water and salt were provided freely (Wang et al., 2011).

\subsection{Vegetation sampling}

In August of 2004 to 2017, we randomly selected 10 quadrats of $50 \mathrm{~cm}$ x $50 \mathrm{~cm}$ in each of twelve plots. The standing crop by species was clipped at the soil surface, oven-dried at $65 \mathrm{degC}$, and weighed. To avoid loss of information (e.g., if random sampling inadvertently avoided large individual shrubs), a systematic sampling method with no paddock replication was used to investigate plant species cover. In August from 
2017 to 2019, a $40 \mathrm{~m}$ x $40 \mathrm{~m}$ sampling area was selected randomly in one of the three repeat plots of each of the CK, LG, MG and HG treatments, choosing plots that were similar in terms of topography and species composition. Four plots were selected to represent the LG, MG, HG plots in Block I and the CK plot in Block II was selected in order to avoid edge effects because the CK plot in Block I is located at the edge of the experiment site (Fig. 1). In this representative sampling area, there were 77 quadrats of $50 \mathrm{~cm} \times 50 \mathrm{~cm}$ (Fig. 2). The quadrat layout was based on mechanical sampling and cover by species was measured in each quadrat. Simultaneously, 9-15 individuals of Artemisia frigida ,Kochia prostrata, Caragana microphylla and Ceratoides latens (shrubs and semi-shrubs, hereinafter, shrubs) were randomly selected from the above grazing plots during 2017 to 2019, and the cover (\%), height (cm), the diameter of the base of the cluster (hereinafter, basal diameter, $\mathrm{cm}$ ), branch number (individuals), and the maximum branch diameter ( $\mathrm{mm}$ ) of the four shrub species were determined. There are five shrub species in experimental region, but Caragana stenophylla has very small individuals and low density and was not found under heavy grazing, and therefore was not systematically sampled.

\subsection{Data analysis}

In order to analyze changes in the above-ground standing crop of shrubby plants over time, we used monitoring data on standing crop by species in August from 2004 to 2017 to calculate the annual cumulative above-ground standing crop of shrubby plants and herbaceous plants, and plotted the dynamic curve of the cumulative above-ground standing crop. One-way ANNOVA was used to test the effects of stocking rate on cover $(\%)$, height $(\mathrm{cm})$, basal diameter $(\mathrm{cm})$, branch number (individuals) and the maximum branch diameter $(\mathrm{mm})$ of four shrubs (Artemisia frigida, Kochia prostrata, Caragana microphylla and Ceratoides latens ) in the plots. Correspondence analysis was used to test the relationship between shrubs and stocking rate, which was analyzed using the importance value of shrubs and the stocking rate gradient. Importance value was calculated as $(I v)=(C r+H r+D r+B N r+B D r) / 5$, where $C r$ (relative cover $)=\mathrm{C}$ (cover of a certain species)/[?]C(total cover of all species), with similar calculations for $\operatorname{Hr}$ (relative height), $\mathrm{Dr}$ (relative basal diameter), $B N r$ (relative branch number) and $B D r$ (relative maximum branch diameter). Variance analysis and correspondence analysis were undertaken using SAS 9.4 (SAS Institute Inc., Cary, NC, USA) at the $P<0.05$ level of significance. To analyze change in the cover of shrubby plants, the plant community was divided into shrubby plants, perennial grasses and other herbaceous plants. Triangular diagrams of the cover of shrubby plants, perennial grasses and other herbaceous plants were plotted using the data on the cover by species monitored in August from 2017 to 2019. All figures were plotted using SigmaPlot Version 12.5 (Systat Software Inc., San Jose, CA, USA).

\section{Results}

\subsection{Dynamic changes of accumulated above-ground standing crop of shrubby and herbaceous plants}

From 2004 to 2017, the dynamic changes of cumulative above-ground standing crop of shrubby and herbaceous plants (Fig. 3) showed that although grazing started at the same time in each treatment, the effects of different stocking rates on above-ground standing crop of plant communities were different. The cumulative above-ground standing crop of shrubby and herbaceous plants both showed a decrease with increasing stocking rate and the difference between the two increased with increasing stocking rate. This suggested that under grazing conditions, a desert steppe rich in shrubs was evolving into a desert steppe that is completely dominated by the herbaceous plant community and that this trend was enhanced under increased stocking rate.

\subsection{Effect of stocking rate on cover of shrubby plants}

As shown in Fig. 4, the cover of shrubby plants decreased with increasing stocking rate. Accordingly, the cover of perennial grasses increased with increasing stocking rate. Fig. 5 further highlights this trend, showing that stocking rate had a limiting effect on shrub cover. The cover of Artemisia frigida, Kochia prostrata ,Caragana microphylla and Ceratoides latens decreased with increasing stocking rate. However, the results of analysis of variance showed that the cover of Artemisia frigida, Caragana microphylla and Ceratoides latens was significantly different at different stocking rates $(P<0.05)$. Although there was a 
decreasing trend in the cover of Kochia prostrata, there was no statistically significant difference under different stocking rates. This suggests that Artemisia frigida, Caragana microphyllaand Ceratoides latens are more sensitive to stocking rate thanKochia prostrata .

\subsection{Response of quantitative characteristics of shrubby plants to stocking rate}

Grazing had a controlling effect on individual shrubs. The individual quantitative characteristics of Artemisia frigida, Kochia prostrata, Caragana microphylla and Ceratoides latensshrubs at different stocking rates are shown in Figure 6.Artemisia frigida was the most sensitive to the stocking rate, followed by Caragana microphylla and Ceratoides latens, while Kochia prostrata had a slow response to stocking rate.

\subsection{Sensitivity analysis of shrub species' response to stocking rate}

The response of the four shrubs to the stocking rate gradient is shown in Figure 7 . The above analysis indicated that the height and coverage of the shrubs decreased significantly with increasing stocking rate, but the correspondence analysis in Figure 6 indicates that Artemisia frigida, Kochia prostrata, Caragana microphylla and Ceratoides latens had significantly different responses to stocking rate. In general, Artemisia frigida and Ceratoides latens were the most sensitive to stocking rate, followed by Caragana microphylla, and finally Kochia prostrata .Kochia prostrata was the most resistant to grazing, followed by Caragana microphylla . Furthermore, the first dimension explained $82.64 \%$ and the second dimension explained $21.39 \%$, which indicated that two dimensions were able to account for $93.4 \%$ of the data and can reflect the information of the original data.

\section{Discussion}

\subsection{Proliferation conditions for shrubs in desert steppe}

Grazing is one of the main factors influencing the dynamics of grassland shrubs (Van Auken, 2000; 2009). The overgrazing hypothesis suggests that chronic overgrazing reduces the biomass of herbaceous plants, which leads to increased resource availability for shrubs, resulting in shrubs becoming the dominant vegetation (Archer et al., 1995; Van De Koppelet al., 2002; Tefera et al., 2007). Our findings showed that when the sheep grazing is introduced or the stocking rate increased, Stipa breviflora desert steppe will not be encroached by shrubs. This finding does not support the hypothesis that chronic overgrazing is a driver of grassland shrub proliferation in the desert steppe. Zhang et al. (2006) studied the responses of Caragana microphylla morphological characteristics to different stocking rates in a typical steppe in Inner Mongolia, and found that the height of Caragana microphylladecreased significantly with increasing stocking rate, which suggested that shrubby plants may resist herbivore feeding via individual miniaturization (Wang et al., 2010). The results of these studies are consistent with the results of our experiment, and support the hypothesis that grazing inhibited encroachment of desert steppe by shrubs (Zhang et al., 2014). Therefore, sheep introduction can prevent the proliferation of shrubs in the desert steppe, while removal of sheep grazing can release shrubs from top-down controls. Sheep grazing is one of barriers limiting shrub encroachment in desert steppe.

\subsection{Response of shrub species to stocking rate}

With increasing duration of grazing history, the cumulative above-ground standing crop of shrubs and grasses increased under low stocking rates (CK, LG), while under high stocking rates (MG, HG) herbaceous plants gradually dominated the plant community. This is closely related to the palatability of grasses and the selective feeding habits of grazing livestock (Molyneux and Ralphs, 1992; Dulamsuren et al., 2008; Staver et al., 2009). Shrubs such as Artemisia frigida, Kochia prostrata, Caragana microphylla and Ceratoides latenshave good palatability in the desert steppe (Yan, 2019), and all are favored by sheep. Therefore, in desert steppe, which has sparse vegetation cover and relatively poor species composition (Han et al., 2007), shrubs are more likely to be consumed by sheep under high stocking rates, leading to their gradual disappearance in the plant community. In this study, the above-ground standing crop of shrubs decreased with increasing stocking rate, which is mainly due to the influence of Artemisia frigida. The change in Artemisia frigida was consistent with those reported by Kemp et al. (2018), who found a significant increase 
in Artemisia frigida under long-term non-grazing and light grazing in an Inner Mongolian desert steppe. Kemp et al. (2018) suggested that Artemisia frigida has good palatability, and that sheep preferentially consumed Artemisia frigida under high stocking rates. Wang et al. (2018) researched the population characteristics of Caragana microphylla across a stocking rate gradient in desert grassland and showed that the height and cover of Caragana microphylla decreased significantly with increasing stocking rate, which indicated that livestock consumption strongly inhibited the growth of Caragana microphylla. The height of shrubs gradually decreased with increasing stocking rate, while the quantitative characteristics of individuals (except for the height of Kochia prostrata, Caragana microphylla and Ceratoides latens ) were highest under LG, indicating that light grazing can inhibit the apical dominance of shrubby plants (Christie et al., 2014).

\subsection{Succession pattern of the desert steppe plant community under a long-term stocking rate gradient}

Plant communities in the desert steppe are developing in two opposite directions across the grazing rate gradient. In the no grazing $(\mathrm{CK})$ treatment, shrubs continue to proliferate and gradually develop into the dominant population in the plant community, indicating a pattern of shrub encroachment under grazing exclosure. Light grazing maintains a mixture of shrubs and herbaceous plants, supporting the results of Kemp et al. (2018). Under long-term high stocking rates (MG, HG), particularly for HG, shrubs tend to disappear, and herbaceous plants dominate the community. Perennial grasses have an absolute advantage in the plant community at high stocking rates (Fig. 4). Among perennial grasses, the dominant species of the plant community, Stipa breviflora, plays an important role (Lv et al, 2020), and its strong grazing tolerance may be related to the fragmentation of plant clusters (Lv et al., 2019) and its sexual reproduction characteristics (Liu et al., 2018). Preferential utilization of shrubs (including seeds and seedlings) by livestock may help maintain desert steppe communities.

\section{Conclusions}

In desert steppe, the introduction of sheep grazing will not lead to shrub encroachment. Without grazing, the desert steppe would be encroached by shrubs, while perennial grasses would have an absolute dominance under chronic high stocking rates. The mixture of shrubby and herbaceous plants was dynamic across the stocking rate gradient and desert steppe plant communities would have multidirectional succession pathways under different long-term stocking rates.

\section{ACKNOWLEDGMENTS}

We thank Liu Bai, Yuanyuan Cui and many students for collecting data in field, and long-term support from Inner Mongolia Academy of Agriculture and Animal Husbandry. This study was supported by the National Science Foundation of China $(31760143,31660679,31770500)$, National Key Research and Development Program of China (2016YFC0500504), Inner Mongolia Key Project (zdzx2018020), and the Innovative Team of Grassland Resources from the Ministry of Education of China (IRT_17R59).

\section{CONFLICT OF INTEREST}

The authors declare no conflicts of interest.

\section{AUTHOR CONTRIBUTIONS}

Guodong Han and Zhongwu Wang conceived and designed the experiments. Baolong Yan performed the experiments and wrote the main manuscript text. Shijie Lv analyzed the data and contributed to manuscript editing. Zhanwen Wang and Xiaohui Song performed the experiments.

\section{DATA ACCESSIBILITY}

All data (standing crop, cover, density and height) from this manuscript are publiaaly available in the FigShare datebase.

\section{ORCID}

Baolong Yan https://orcid.org/0000-0002-1873-3726 


\section{REFERENCES}

Altesor, A., Pineiro, F., \& Lezama, R. (2006). Ecosystem changes associated with grazing in subhumid South American grasslands. Journal of Vegetation Science, 17, 323-332.

Archer, S. (1994). Woody plant encroachment into southwestern grasslands and savannas: rates, patterns and proximate causes. In: Vavra, M., Laycock, W.A., Pieper, R.D.(Ed.), Ecological implications of livestock herbivory in the West. Denver: Society for Range Management, pp. 13-63.

Archer, S., Schimel, D., \& Holland, E. (1995). Mechanisms of shrubland expansion: land use, climate or $\mathrm{CO}_{2}$ ? Climatic Change, 29, 91-99.

Asner, G.P., Elmore, A.J., Olander, L.P., Martin, R.E., \& Harris, A.T. (2004). Grazing systems, ecosystem responses, and global change.Annual Review of Environment 8 Resources , 29, 261-299.

Barbosa da Silva, F.H., Arieira, J., Parolin, P., Nunes da Cunha, C., \& Junk, W.J. (2016). Shrub encroachment influences herbaceous communities in flooded grasslands of a neotropical savanna wetland. Applied Vegetation Science, 19, 391-400.

Belsky, A.J., \& Blumenthal, D.M. (2010). Effects of livestock grazing on stand dynamics and soils in upland forests of the interior west. Conservation Biology, 11, 315-327.

Briske, D. (2017). Rangeland systems: processes, management and challenge. Cham: Springer International Publishing $A G$, pp. 33-46.

Brown, J., \& Archer, S. (1999). Shrub invasion of grassland: recruitment is continuous and not regulated by herbaceous biomass or density. Ecology , 80, 2385-2396.

Case, M.F., \& Staver, A.C. (2017). Fire prevents woody encroachment only at higher-than-historical frequencies in a South African savanna. Journal of Applied Ecology, 54, 955-962.

Christie, K.S., Ruess, R.W., Lindberg, M.S., \& Mulder, C.P. (2014). Herbivores influence the growth, reproduction, and morphology of a widespread arctic willow. PLoS One, 9, e101716.

de Dios, V.R., Weltzin, J.F., Sun, W., Huxman, T.E. \& Williams, D.G. (2014). Transitions from grassland to savanna under drought through passive facilitation by grasses. Journal of Vegetation Science , 25, 937-946.

Devine, A.P., Mcdonald, R.A., Quaife, T., \& Maclean, I.M.D. (2017). Determinants of woody encroachment and cover in African savannas. Oecologia , 183, 939-951.

Dulamsuren, C., Hauck, M., \& Muhlenberg, M. (2008). Insect and small mammal herbivores limit tree establishment in northern Mongolian steppe.Plant Ecology , 195, 143-156.

Eldridge, D.J., Bowker, M.A., Maestre, F.T., Erin, R., Reynolds, J.F., \& Whitford, W.G. (2011). Impacts of shrub encroachment on ecosystem structure and functioning: towards a global synthesis. Ecology Letters , 14, 709-722.

February, E.C., Higgins, S.I., Bond, W.J., \& Louise, S. (2013). Influence of competition and rainfall manipulation on the growth responses of savanna trees and grasses. Ecology, 94, 1155-1164.

Friedel, M.H. (1985). The population structure and density of central Australian trees and shrubs, and relationships to range condition, rabbit abundance and soil. Rangeland Journal , 7, 130-139.

Goheen, J.R., Keesing, F., Allan, B.F., Ogada, D., \& Ostfeld, R.S. (2004). Net effects of large mammals on Acacia seedling survival in an African savanna. Ecology , 85, 1555-1561.

Graz, F.P. (2010). The woody encroachment puzzle: gathering pieces.Ecohydrology , 1, 340-348.

Han, G., Jiao, S., Biligetu, \& Aodenggaowa. (2007). Effects of plant species diversity and productivity under different stocking rates in theStipa breviflora Griseb. Desert steppe. Acta Ecologica Sinica, 27, 182-188. 
Keddy, P.A. (1992). Assembly and response rules: Two goals for predictive community ecology. Journal of Vegetation Science, 3, 157.

Lin, Y., \& Bai, Y. (2010). Responses of aboveground net primary production and population structure of Caragana microphylla to prescribed burning in a typical steppe of Inner Mongolia. Acta Prataculturae Sinica , 19, 170-178.

Liu, W., Wang, T., Zhang, S., Ding, L., \& Wei, Z. (2018). Grazing influences Stipa breviflora seed germination in desert grasslands of the Inner Mongolia Plateau. Peerj , 6, e4447.

Lohmann, D., Tietjen, B., Blaum, N., Joubert, D.F., \& Jeltsch, F. (2014). Prescribed fire as a tool for managing shrub encroachment in semi-arid savanna rangelands. Journal of Arid Environment, 107, 49-56.

Lv, S., Yan, B., Wang, Z., Han, G., \& Kang, S. (2019). Grazing intensity enhances spatial aggregation of dominant species in a desert steppe. Ecology and Evolution , 9, 6138-6147.

Lv, S., Yan, B., Wang, Z., Wang, Z., Song, X., .. Han, G. (2020). Dominant species' dominant role and spatial stability are enhanced with increasing stocking rate. Science of The Total Environment, 730, 138900.

Madany, M.H., \& West, N.E. (1983). Livestock grazing-fire regime interactions within montane forests of Zion National Park, Utah.Ecology , 64, 661-667.

Molyneux, R., \& Ralphs, M. (1992). Plant toxins and palatability to herbivores. Journal of Range Management , 45, 13-18.

Painter, E.L., \& Belsky, A.J. (1993). Application of herbivore optimization theory to rangelands of the western United States.Ecological Applications , 3, 2-9.

Staver, C.A., Bond, W.J., Stock, W.D., Van Rensburg, S.J., \& Waldram, M.S. (2009). Browsing and fire interact to suppress tree density in an African savanna. Ecological Applications , 19, 1909-1919.

Stokes, C., \& Archer, S. (2010). Niche differentiation and neutral theory: An integrated perspective on shrub assemblages in a parkland savanna. Ecology , 91, 1152-1162.

Tefera, S., Snyman, H.A., \& Smit, G.N. (2007). Rangeland dynamics of southern Ethiopia: (2). Assessment of woody vegetation structure in relation to land use and distance from water in semi-arid Borana rangelands. Journal of Environmental Management, 85, 443-452.

Tews, J., Schurr, F., \& Jeltsch, F. (2004). Seed dispersal by cattle may cause shrub encroachment of Grewia flava on southern Kalahari rangelands. Applied Vegetation Science, 7, 89-102.

Van Auken, O. (2000). Shrub invasions of North American semiarid grasslands. Annual Review of Ecology and Systematics , 31, 197-215.

Van Auken, O. (2009). Causes and consequences of woody plant encroachment into western North American grasslands. Journal of Environmental Management, 90, 2931-2942.

Van Auken, O.W., \& Smeins, F. (2008). Western North American Juniperus communities: patterns and causes of distribution and abundance. In: Van Auken, O.W. (Ed.), Western North American Juniperus Communities: A Dynamic Vegetation Type. New York: Springer, pp. 3-18.

Van De Koppel, J., Rietkerk, M., \& Van Langevelde, F. (2002). Spatial heterogeneity and irreversible vegetation change in semiarid grazing systems. The American Naturalist , 159, 209-2018.

Wang, L., Wang, Y., Wang, K., Xie, L., \& Ma, C. (2018). Effect of grazing on quantitative characteristics of Caragana microphyllapopulation. Pratacultural Science, 35, 800-806.

Wang, W., Liang, C., Liu, Z., \& Hao, D. (2000). Analysis of the plant Individual behaviour during the degradation and restoring succession in steppe community. Chinese Journal of Plant Ecology , 24, 268-274. 
Wang, Z., Jiao, S., Han, G., Zhao, M., Willms, W.D., ... Havstad, K.M. (2011). Impact of stocking rate and rainfall on sheep performance in a desert steppe. Rangeland Ecology $\& 3$ Management, 64, 249-256.

Wei, Z., Han, G., Zhang, G., \& Li, D. (2013). Study of desert steppe ecosystems in China. Beijing: Science Pres s, pp. 33-49.

Yan, B. (2019). Shrub-herbaceous interactions in a desert steppe under different stocking rate. Hohhot: Inner Mongolia Agricultural University, pp. 200.

Zhang, Y., Gao, Q., Xu, L., Yu, M., \& Tian, Y. (2014). Shrubs proliferated within a six-year exclosure in a temperate grassland- spatiotemporal relationships between vegetation and soil variables.Science in Cold and Arid Regions , 36, 139-149.

Zhang, Z., Wang, S., Nyren, P., \& Jiang, G. (2006). Morphological and reproductive response of Caragana microphylla to different stocking rates. Journal of Arid Environment , 67, 671-677.

Figure legends:

Figure1 Schematic diagram of the grazing experiment plots. Dark color plots indicate systematic sampling plots. The grazing experiment plots (each ca. $4.4 \mathrm{hm}^{2}$ ) were arranged in a randomized complete block design, which included four stocking rate treatments with three repeats of each stocking rate. The stocking rates were $0,0.91,1.82,2.71$ sheep $^{*} \mathrm{hm}^{-2}$ *half year $^{-1}$ representing no grazing (CK), light grazing (LG), moderate grazing (MG), and heavy grazing ( $\mathrm{HG})$, respectively.

Figure 2 The sample distribution for systematic sampling. The sample-plot size was $40 \mathrm{mx} 40 \mathrm{~m}$, each square was $2.5 \mathrm{mx} 2.5 \mathrm{~m}$, and the solid circles represent the sample points.

Figure 3 Dynamic changes of accumulated above-ground standing crop of shrubby and herbaceous plants during 2004-2017. CK, no grazing; LG, light grazing; MG, moderate grazing; HG, heavy grazing.

Figure 4 Triangular diagrams of the cover of shrubby plants, perennial grasses and other herbaceous plants. CK, no grazing; LG, light grazing; MG, moderate grazing; HG, heavy grazing.

Figure 5 Cover of four species under different stocking rates. Mean values (+-SD; $\mathrm{n}=9-15$ ) of (A ) Artemisia frigida , (B) Kochia prostrata , (C) Caragana microphylla and (D)Ceratoides latens . Different lowercase letters indicate that grand means differ significantly between the grazing treatments $(P<0.05)$. CK, no grazing; LG, light grazing; MG, moderate grazing; HG, heavy grazing.

Figure 6 The quantitative characteristics of four species under different stocking rates. Mean values (+$\mathrm{SD} ; \mathrm{n}=9-15)$ of (A-D )Artemisia frigida, (E-H) Kochia prostrata, (I-L)Caragana microphylla and (M-P) Ceratoides latens. Different lowercase letters indicate that grand means differ significantly between the grazing treatments $(P<0.05)$. CK, no grazing; LG, light grazing; MG, moderate grazing; HG, heavy grazing.

Figure 7 Correlation diagram of four shrubs and stocking rate gradient. A. fri, Artemisia frigida; K. pro ,Kochia prostrata ; C. mic, Caragana microphylla ;C. lat, Ceratoides latens . CK, no grazing; LG, light grazing; MG, moderate grazing; HG, heavy grazing.

\begin{tabular}{|c|c|c|c|c|c|c|c|c|c|c|c|}
\hline CK1 & LG1 & HG1 & MG1 & HG2 & CK2 & MG2 & LG2 & LG3 & CK3 & MG3 & HG3 \\
\hline \multicolumn{3}{|c|}{ BLOCK I } & \multicolumn{3}{c|}{ BLOCK II } & & & & \\
\hline
\end{tabular}




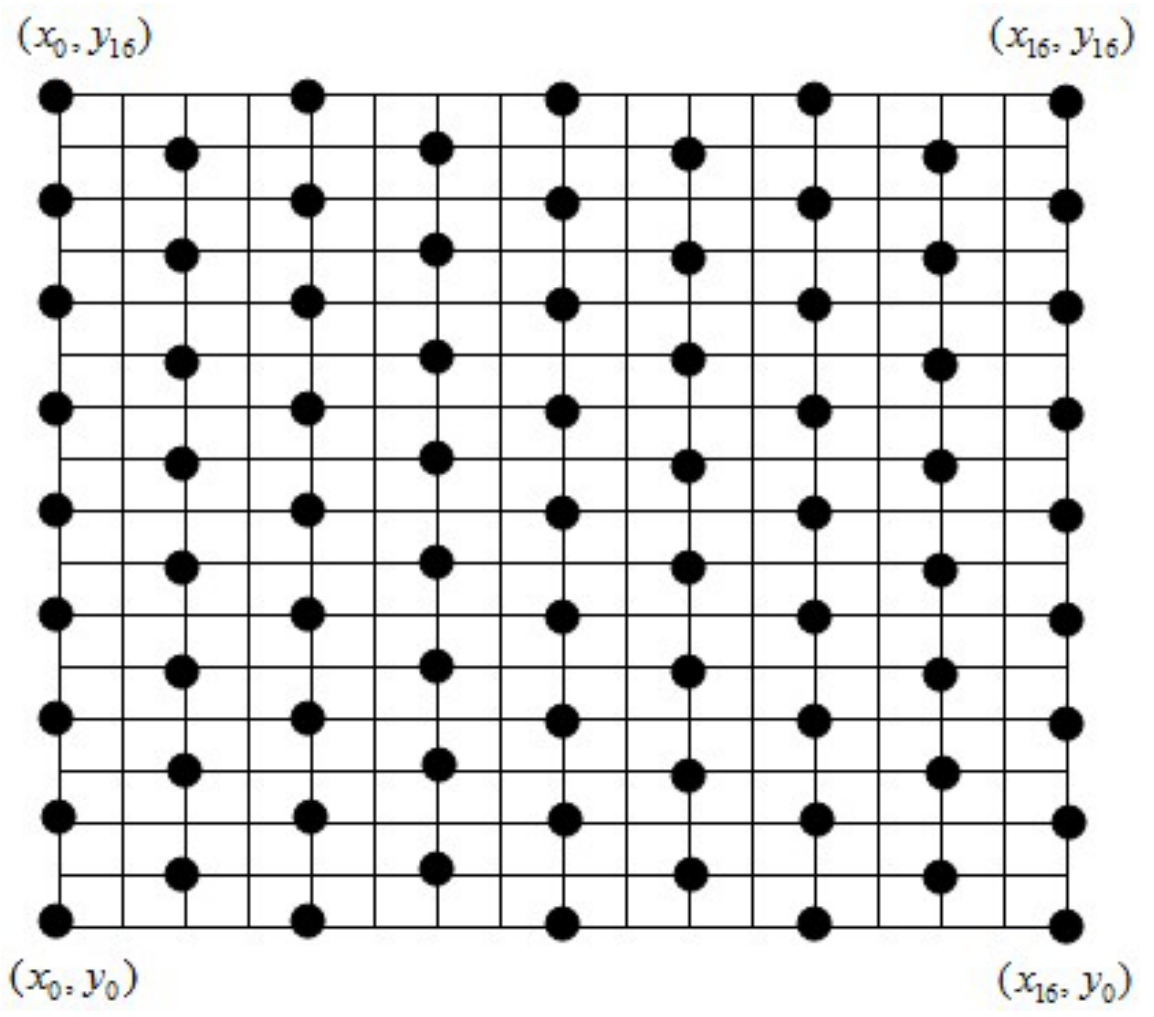



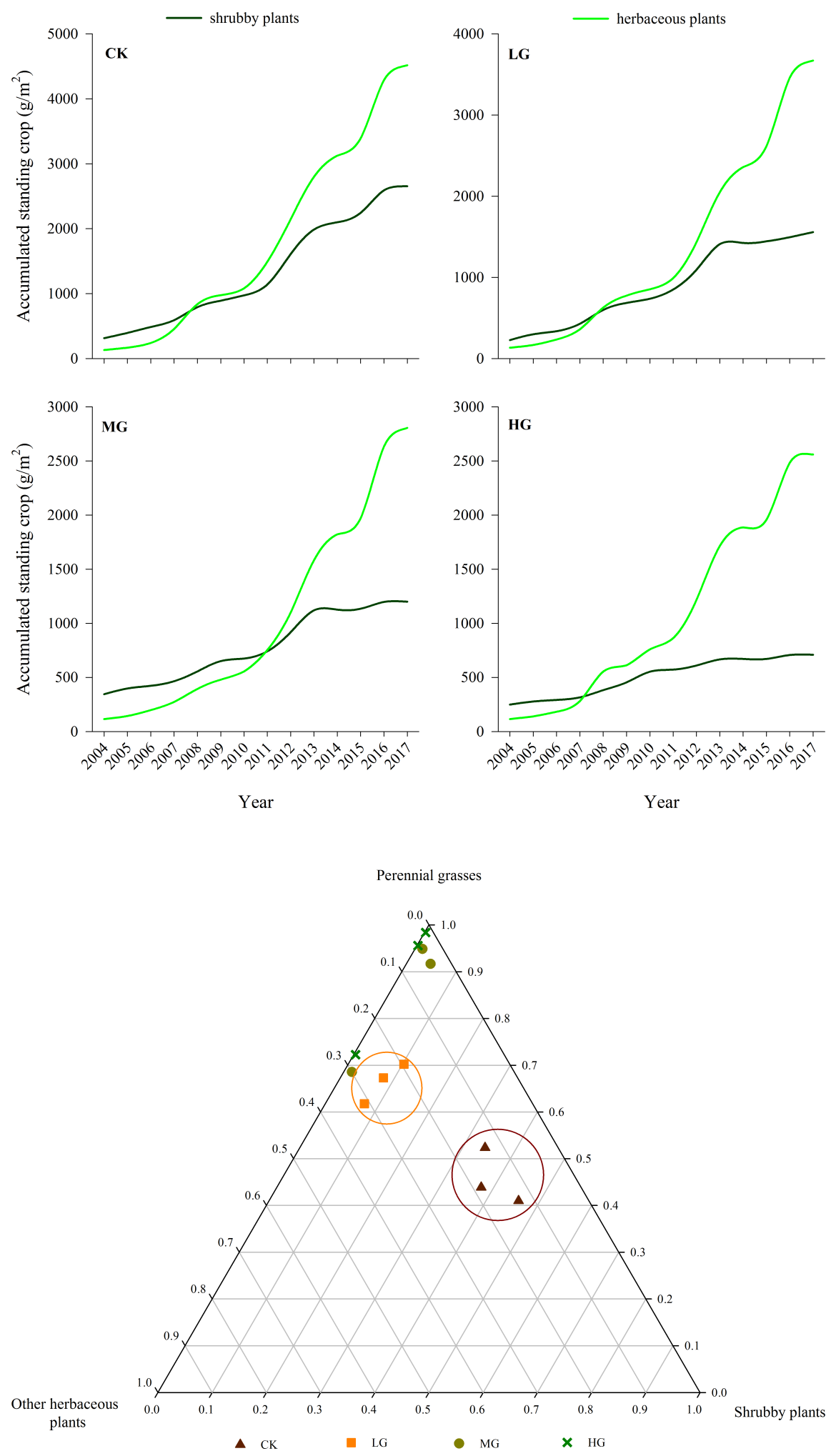

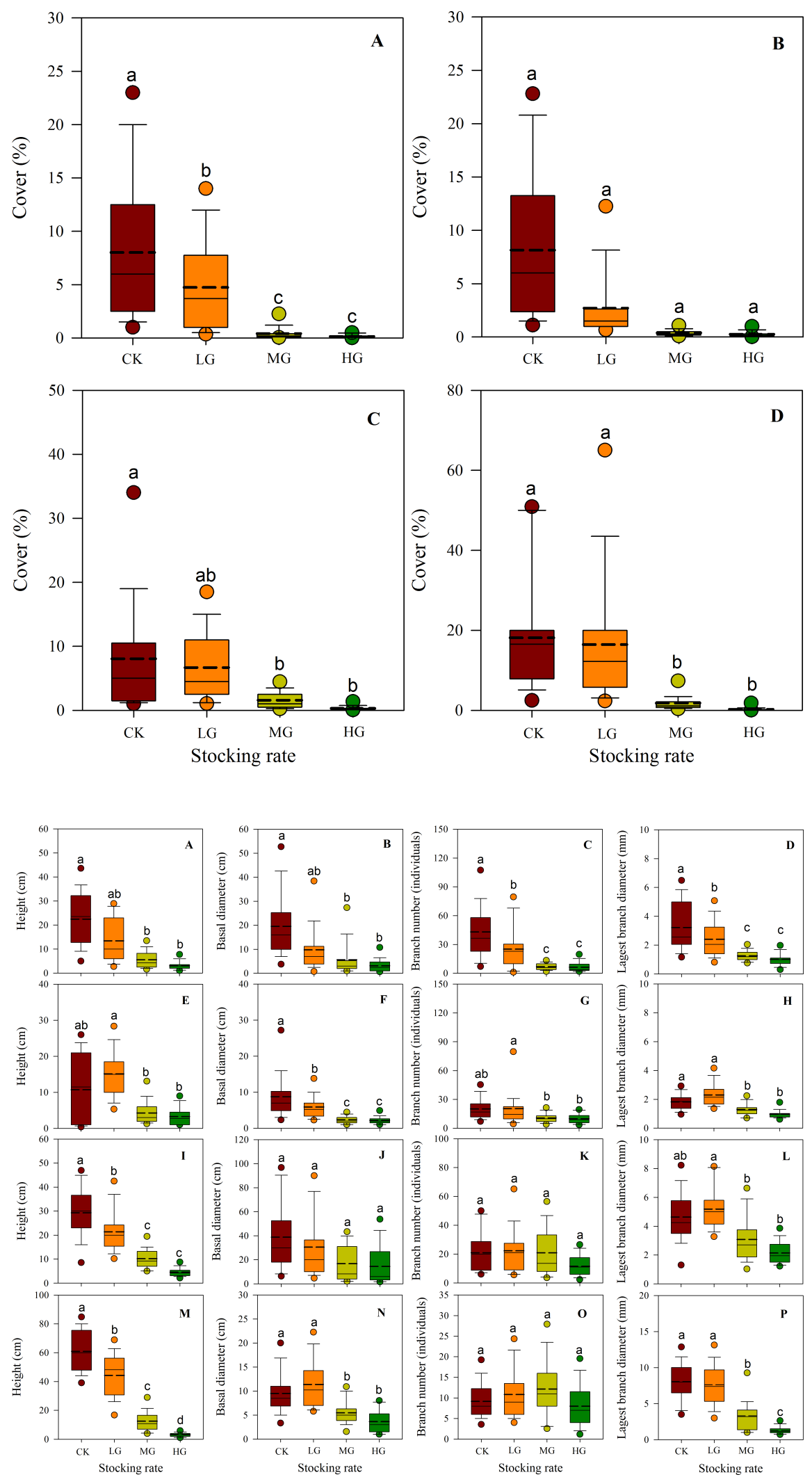


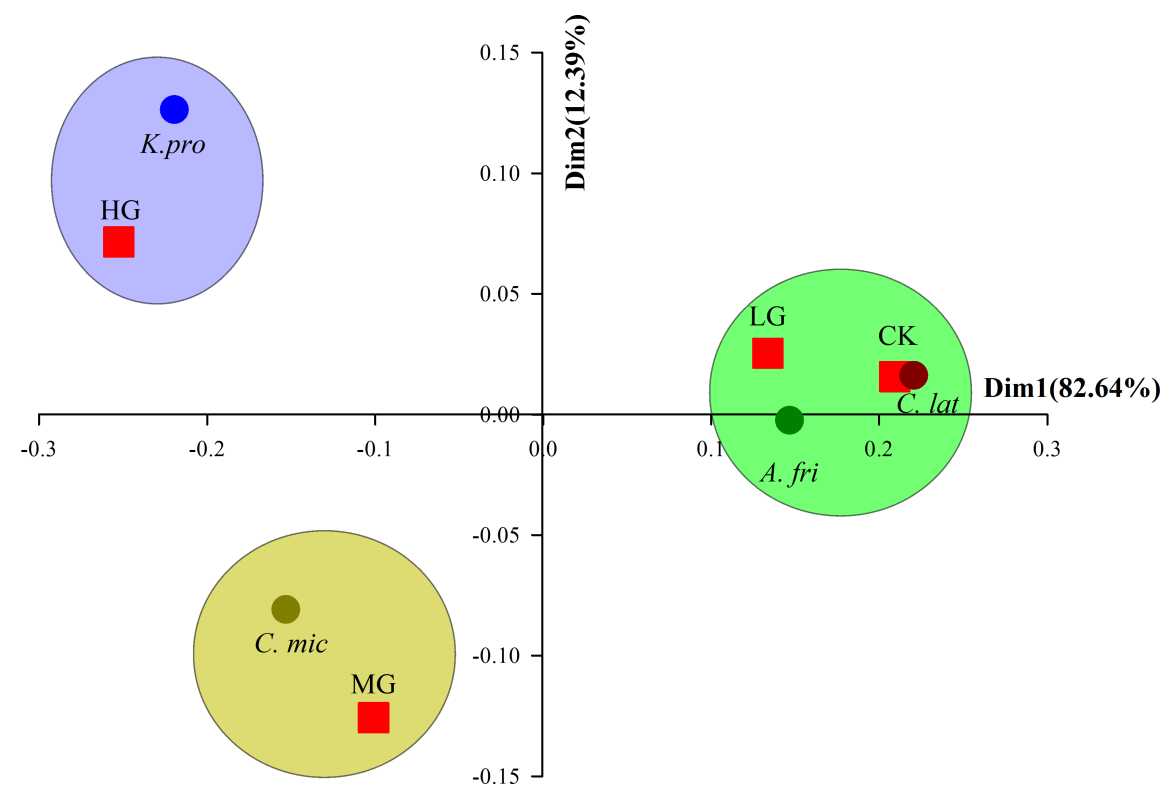

